Jurnal Penelitian, Vol. 10, No. 2, Agustus 2016

\title{
EVALUASI PROGRAM PENDAMPINGAN PENGEMBANGAN KEPRIBADIAN MUSLIM INTEGRAL (P3KMI) DI JURUSAN PENDIDIKAN GURU RAUDHATUL ATHFAL FAKULTAS ILMU TARBIYAH DAN KEGURUAN IAIN SURAKARTA TAHUN 2016
}

\author{
Subar Junanto \\ IAIN Surakarta, Jawa Tengah, Indonesia \\ subarjunanto@yahoo.co.id
}

\begin{abstract}
This study uses a mix method, which incorporates quantitative and qualitative research. This research was conducted in evaluating Program Pendampingan Pengembangan Kepribadian Muslim Integral (P3KMI) Raudhatul Athfal Departement At Tarbiyah And Teacher Training Faculty IAIN Surakarta in 2016. mentee and mentor of P3KMI. Data collection techniques using observation, interviews, documentation and questionnaire. The focus of the evaluation in the form of context, input, process and product of P3KMI. Data were analyzed using qualitative analysis and statistical analysis. The results of this study show that: 1) Evaluation Context P3KMI program is urgently needed by the student. Among other reasons because $p 3 \mathrm{kmi}$ program is an obligation of the faculty, and the lack of ability of students in the field of Religious. 2) Evaluation of student input characteristics P3KMI views of gender, comprised of 51 women and 2 men. While the views of educational background, consisting of 43 graduates from the general (SMA / SMK) and 11 religious graduate $M A$ ( Ponpes). 3) Process Evaluation Results of the evaluation process showed less activity in the category mentee with a good percentage of $18.86 \%$, the percentage is quite amounting to $35.84 \%$, and the
\end{abstract}


percentage is less by $45.28 \%$. While the results of the evaluation process for mentor activity in both categories with a percentage of $85.71 \%$.4) Product Evaluation Based on the tests that have been conducted, the results of student learning in the category passed by $18.86 \%$ and the repeat / remidi by $81.14 \%$.

Keywords: Evaluation, P3KMI.

\begin{abstract}
Abstrak
Penelitian ini menggunakan metode mix method, yaitu menggabungkan penelitian kuantitatif dan penelitian kualitatif. Penelitian ini dilakukan di mengevaluasi Program Pendampingan Pengembangan Kepribadian Muslim Integral (P3KMI) di Jurusan Pendidikan Guru Raudhatul Athfal, Fakultas Keguruan dan Ilmu Pendidikan IAIN Surakarta tabun 2016. Subyek penelitian terdiri dari mentee dan mentor P3KMI. Teknik pengumpulan data menggunakan observasi, wawancara, dokumentasi dan angket. Fokus evaluasi berupa context,input,process dan product dari P3KMI. Teknik analisis data menggunakan analisis kualitatif dan analisis statistik. Hasil penelitian ini menunjuk.kan babwa: 1) Evaluasi Context Program $p 3 k$ mi ini sangat dibutubkan oleh mahasiswa. Alasannya antara lain karena program p3kmi merupakan kewajiban dari fakultas, dan kurangnya kemampuan mahasiswa dalam bidang Keagamaan. 2) Evaluasi Input Karakteristik mahasiswa program P3KMI dilihat dari jenis kelamin, terdiri dari 51 perempuan dan 2 laki-laki. Sedangkan dilibat dari latar belakang pendidikan, terdiri dari 43 orang lulusan umum (SMA/SMK) dan 11 orang lulusan keagamaan (MA) Ponpes). 3) Evaluasi Proses Hasil evaluasi proses menunjuk.kan aktivitas mentee dalam kategori kurang dengan presentase baik sebesar 18,86\%, presentase cukup sebesar 35,84\%, dan presentase kurang sebesar 45,28\%. Sedangkan hasil evaluasi proses untuk. aktivitas mentor dalam kategori baik dengan presentase sebesar 85,71 \%.4) Evaluasi Product Berdasarkan tes yang telab dilaksanakan, hasil belajar mahasiswa yang masuk kategori lulus sebesar 18,86\% dan yang mengulang/remidi sebesar 81,14\%.
\end{abstract}

Kata Kunci: Evaluasi, Program Pendampingan Pengembangan Kepribadian Muslim Integral (P3KMI). 


\section{A. Pendahuluan}

Formulasi visi dan misi PTAI yaitu (1) Menyelenggarakan program pendidikan akademik, mengemban misi sebagai lembaga keilmuan atau lembaga pengembangan kajian ilmuilmu agama Islam; (2) Menyelenggarakan program pendidikan professional, mengemban misi untuk menyiapkan calon-calon ulama professional atau tenaga professional yang ulama sesuai dengan bidang keahlian yang ditekuninya; (3) Mengemban misi pembinaan dan pengembangan umat Islam agar memiliki concern dan komitmen terhadap ajaran dan nilai Islam dalam segala aspek kehidupan, yang dilandasi oleh pemahaman dan wawasan keilmuan Islam ${ }^{1}$. Sebagai salah satu bagian dari PTAI maka IAIN Surakarta khususnya Fakultas Ilmu Tarbiyah dan Keguruan berusaha menjadi rujukan sebagai pusat Ilmu dan Budaya Islami ( Center of Knowledge and Islamic Culture).

Menurut pandangan Islam, lembaga pendidikan formal termasuk di dalamnya perguruan tinggi tidak hanya berfungsi sebagailembaga transfer ilmu pengetahuandan pengembangannya saja, melainkan juga sebagai tempat untuk pembentukan akhlak al karimah. dan lebih di tekankan lagi di perguruan tinggi agama islam dan apabila fungsi keterpaduan (ilmu dan amal) mampu untuk dioptimalkan tidak menutup kemungkinan munculnya cendekiawan cendekiawan muslim yang tidak hanya cerdas secara teoristis tetapi juga mampu mengimplementasikan ilmunya dalam tataran realita. Fungsi pembinaan keagamaan bagi mahasiswa di Perguruan Tinggi Islam bukan hanya dari segi kognitif saja tetapi lebih merupakan penanaman spiritualitas yang bermuara pada pembentukan akhlak mulia (aklahqul karimah). Untuk itu diperlukan suatu program yang memberikan perhatian pada aspek pembentukan Akhlak Karimah bagi mahasiswa sehingga nantinya mampu menjadi pemimpin yang mampu membangun sebuah peradapan. Maka dari itu dibentuklah Program Pendampingan Pengembangan Kepribadian Muslim Integral (P3KMI).

Program ini juga dicetuskan dalam rangka membantu

${ }^{1}$ Muhaimin, Wacana Pengembangan Pendidikan Islam, (Yogyakarta: Pustaka Pelajar, 2004), hlm. 55. 
untuk meningkatkan kompetensi lulusan Fakultas Ilmu Tarbiyah dan Keguruan. Tujuan dari P3KMI adalah membekali mahasiswa dengan kemampuan dasar keislaman baik secara ilmu dan amal (BTA, Pengembangan Kepribadian, Tsaqofah Islamiyah dan Praktek Ibadah). Sehingga target terpenuhinya kompetensi mahasiswa peserta baik kompetensi individual maupun kompetensi sosial dapat tercapai.

\section{B. Pembahasan}

\section{Program Pendampingan dan Pengembangan Kepribadian Muslim Integral (P3KMI)}

Program Pendampingan dan Pengembangan Kepribadian Muslim Integral (P3KMI) di jurusan Pendidikan Guru Raudhatul Athfal, merupakan kegiatan yang terangkai dan menyatu dengan kegiatan Praktek Keahlian dan Praktik Ibadah yang bersifat Ko-Kurikuler. Setiap mahasiswa di jurusan Pendidikan Guru Raudhatul Athfal Fakultas Ilmu Tarbiyah dan Keguruan IAIN Surakarta wajib lulus dari Program Pendampingan dan Pengembangan Kepribadian Muslim Integral (P3KMI) karena kegiatan ini mengikat dan menjadi salah satu persyaratan dalam mengikuti kegiatan akademik lainnya, yaitu: Micro Teaching, PPL, menempuh ujian sidang seminar dan munaqosyah.

Realita di lapangan menunjukkan masih terdapat berbagai kelemahan dalam pelaksanaan P3KMI antara lain masalah buku panduan dan kurikulum. Toto Subarto dan Ja'far Assagaf di Jurnal At Tahrir Vol 14, No 1 (2014) dengan judul Membendung Arus Paham Keagamaan Radikal Di Kalangan Mahasiswa PTKIN memberikan kesimpulan : 1. Banyaknya referensi Gerakan Tarbiyah yang dijadikan rujukan Panduan P3KMI, secara ideologis, dapat dikatakan: materi kurikulum dalam panduan ini tidak cukup kuat untuk melakukan counter terhadap paham keagamaan Islam radikal bagi mahasiswa FITK IAIN Surakarta. 2. Melihat materi kurikulumnya yang merupakan modul mentoring Gerakan Tarbiyah dalam melakukan pengkaderan melalui halaqah, usroh, mantuba, mutaba'ah, dan materi-materi lainnya,kuat dugaan bahwa buku Panduan P3KMI itu menjadi bagian dari Gerakan 
Tarbiyah itu sendiri, atau setidaknya menjadi penyemai ideologi Gerakan Tarbiyah ${ }^{2}$.

Berdasarkan hasil awal observasi lapangan masalah lain yang dihadapi oleh P3KMI, diantaranya adalah masalah pelaksanaan pembelajaran yang kadang tidak sesuai dengan jadwal pembelajaran yang meliputi waktu pelaksanaan dan durasinya, selain materi program terkadang tidak sesuai dengan yang menjadi target pelaksanaan P3KMI. Persoalan lain adalah kualifikasi mentor P3KMI yang belum sesuai dengan kompetensi yang diharapkan. Segala permasalahan ini tentu sangat berpengaruh terhadap kelangsungan proses pelaksanaan program di P3KMI yang pada akhirnya menimbulkan ketidakmaksimalan output program. Untuk itu diperlukan evaluasi yang terstruktur sehingga bisa meningkatkan kualitas Program Pendampingan Pengembangan Kepribadian Muslim Integral (P3KMI)

Berdasarkan paparan di atas, penulis tertarik untuk melakukan penelitian terkait evaluasi Program Pendampingan Pengembangan Kepribadian Muslim Integral (P3KMI) di Jurusan Pendidikan Guru Raudhatul Athfal, Fakultas Keguruan dan Ilmu Pendidikan IAIN Surakarta dengan fokus penelitian menggunakan evaluasi model CIPP (context, input, process, product) dari Stufflebeam.

Menurut Ralph Tyler, evaluasi ialah proses yang menentukan sampai sejauh mana tujuan pendidikan dapat dicapai ${ }^{3}$. Maclcolm, Provus mengatakan valuasi hendaknya membantu pengembangan, implementasi, kebutuhan suatu program, perbaikan program, pertanggungjawaban, seleksi, motivasi, menambah pengetahuan dan dukungan dari mereka yang terlibat. Berbagai macam evaluasi yang dikenal dalam bidang kajian ilmu. Salah satunya adalah evaluasi program yang banyak digunakan dalam kajian kependidikan ${ }^{4}$. Evaluasi program

2 Toto Suharto \& Ja'far Assagaf, Membendung Arus Paham Keagamaan Radikal Di Kalangan Mahasiswa PTKIN, (Ponorogo : At Tahrir, 2014), hlm. 4.

${ }^{3}$ Tyler, RW, Basic principles of curriculum and instruction, (Chicago: University of Chicago, 1967), hlm. 69.

4Provus, M., Discrepency evaluation, (Barkeley: MacCutchan, 1971), hlm. 6. 
mengalami perkembangan yang berarti sejak Ralph Tyler, Scriven, John B. Owen, Lee Cronbach, Daniel Stufflebeam, Marvin Alkin, Malcolm Provus, R. Brinkerhoff dan lainnya. Banyaknya kajian evaluasi program yang membawa implikasi semakin banyaknya model evaluasi yang berbeda cara dan penyajiannya, namun jika ditelusuri semua model bermuara kepada satu tujuan yang sama yaitu menyediakan informasi dalam kerangka "decision" atau keputusan bagi pengambil kebijakan. Jadi evaluasi adalah proses yang digunakan untuk menilai

Konsep model evaluasi CIPP (Context, Input, Process and Product) model ini pertama kali ditawarkan oleh Stufflebeam sebagai hasil usahanya mengevaluasi ESEA (The elementary and secondary education ACT). Menurut Stufflebeam tujuan penting evaluasi adalah bukan membuktikan tapi untuk memperbaiki. The CIPP " a approach is ased the viw that the most important purpose of evaluation is not to prove but to improve" . Evaluasi CIPP dapat diterapkan diberbagai bidang, seperti pendidikan ,manajemen, perusahaaan dan sebagainya serta dalam berbagai jenjang baik proyek, program maupun institusi. Dalam bidang pendidikan Stufflebeam menggolongkan system pendidikan atas 4 dimensi yaitu, context, input, process dan product sehingga model evaluasi diberi nama CIPP sehingga model evaluasinya diberi nama model diberi nama CIPP model yang merupakan singkatan keempat dimensi tersebut.

a. Evaluasi konteks (Context Evaluations); evaluasi konteks menggambarkan lingkungan yang relevan, identifikasi kebutuhan dan kesempatan dan diagnosa pada permasalahan tertentu contoh analisis program pembelajaran.

b. Evaluasi masukan (input evaluation) memberikan informasiuntuk menentukan bagaimana memanfaatkan sumber daya untuk mencapai tujuan program dengan baik. Evaluasi input digunakan untuk memutuskan apakah bantuan dari luar penting dan membantu

${ }^{5}$ Stufflebeam, DL, Educational Evaluation and Decising Making ( Illionis: Hasca Illinois Pecocok Publicers Inc, 1972), hlm. 118. 
menentukan strategi umum dalam merencanakan dan mendesain program. Hasil evaluasi input sering dipandang sebagai kebijakan, anggaran, skedul, proposal dan prosedur.

c. Evaluasi proses (Process evaluation) memberi umpan balik pada tanggung jawab individu dalam hal implementasi. Hal ini dapat dipenuhi dengan memantau sumber kegagalan, memberikan informasi dalam memutuskan rencana awal selama implementasi dan menjelaskan apa yang benar-benar terjadi.

d. Evaluasi produk (Product evaluation) mengukur dan mentafsirkan pencapaian tujuan program. Evaluasi produk juga mengukur dampak yang diharapkan dan dampak yang tidak diharapkan. Evaluasi pada level ini biasa dilakukan selama dan setelah program dilaksanakan ${ }^{6}$.

Program Pendampingan Pengembangan Kepribadian Muslim Integral (P3KMI ) merupakan usaha dipihak Fakultas dalam rangka meningkatkan kompentensi lulusan Fakultas Ilmu Tarbiyah dan Keguruan IAIN Surakarta yang secara Teknis dilaksanakan oleh tim P3KMI .Pelaksanaan program ini terdiri dari kegiatan mentoring bagi seluruh peserta yang terdaftar di Fakultas Ilmu Tarbiyah dan Keguruan dan ikut dalam Placement Test yang di adakan oleh tim pelaksana, kemudiaan akan dikelompokkan dengan sistem dinamika kelompok kecil yang terdiri 8-10 peserta setiap kelompok kemudian akan dipandu oleh seorang mentor yang telah di tunjuk oleh Tim pelaksana dan lulus kualifikasi mentor. Selain kegiatan di atas guna tercapainya tujuan dari pelaksanaan P3KMI ini perlu diadakan kegiatan penunjang berupa suplemen bagi para peserta dan para mentor misalnya dengan mengadakan Out Bond, MABIT, AMT, TOT bagi mentor yang kesemuaanya di sesuaikan oleh kebutuhan dari para peserta maupun mentor.

${ }^{6}$ Suharsimi Arikunto, Dasar-Dasar Evaluasi Pendidikan (Jakarta: Rhineka Cipta, .1998), hlm. 17. 


\section{Pendekatan Penelitian}

Pelaksanaan penelitian ini dilakukan untuk mengetahui hasil evaluasi model CIPP untuk Program Pendampingan Pengembangan Kepribadian Muslim Integral (P3KMI) di Jurusan Pendidikan Guru Raudhatul Athfal, Fakultas Keguruan dan Ilmu Pendidikan IAIN Surakarta tahun 2016.

Penelitian ini menggunakan mix method, yaitu menggabungkan penelitian kuantitatif dan pennelitian kualitatif. Penelitian kuantitatif adalah penelitian yang penyajian hasil penelitiannya menggunakan angka-angka. Sedangkan penelitian kualitatif adalah penelitian yang mengutamakan pengumpulan data dengan berdasarkan atas ungkapan-ungkapan yang telah dieksplorasikan dan diungkapkan oleh para responden.

Penelitian kuantitatif untuk mengevaluasi tentang Input dan Product. Sedangkan penelitian kualitatif ini untuk mengevaluasi Context dan Process. Subyek Peneliti Program Pendampingan Pengembangan Kepribadian Muslim Integral (P3KMI) di Jurusan Pendidikan Guru Raudhatul Athfal,Fakultas Keguruan dan Ilmu Pendidikan IAIN Surakarta yang terdiri dari mentee dan mentor P3KMI. Teknik pengumpulan data menggunakan observasi, wawancara, dokumentasi dan angket. Fokus evaluasi berupa context,input,process dan product dari P3KMI. Teknik analisis data menggunakan analisis kualitatif dan analisis statistik.

\section{a. Tempat dan Waktu Penelitian}

Penelitian dilakukan di Program Pendampingan Pengembangan Kepribadian Muslim Integral (P3KMI) di Jurusan Pendidikan Guru Raudhatul Athfal, Fakultas Keguruan dan Ilmu Pendidikan IAIN Surakarta tahun 2016.

\section{b. Subjek Penelitian}

Subyek penelitian ini adalah Program Pendampingan Pengembangan Kepribadian Muslim Integral (P3KMI) di Jurusan Pendidikan Guru Raudhatul Athfal,Fakultas Keguruan dan Ilmu Pendidikan IAIN Surakarta yang terdiri dari mentee dan mentor P3KMI. Teknik sampling yang digunakan adalah total sampling, 
yaitu seluruh mentor dan mentee dijadikan subjek penelitian sejumlah 53 mentee dan 6 mentor.

\section{c. Jenis dan Pendekatan Penelitian}

Jenis Penelitian ini dakategorikan sebagai penelitian evaluasi. Penelitian evaluasi merupakan kegiatan penelitian untuk mengumpulkan data, menyajikan informasi yang akurat dan objektif yang terjadi di lapangan terutama mengenai pelaksanaan Program Pendampingan Pengembangan Kepribadian Muslim Integral (P3KMI) di Jurusan Pendidikan Guru Raudhatul Athfal, Fakultas Keguruan dan Ilmu Pendidikan IAIN Surakarta. Pendekatan yang digunakan dalam penelitian ini adalah kuantitatif dan kualitatif. Data kuantitatif untuk mendapatkan hasil evaluasi yang mendalam tentang Program Pendampingan Pengembangan Kepribadian Muslim Integral (P3KMI). Sementara data kualitatif berupa data tentang pelaksanaan Program Pendampingan Pengembangan Kepribadian Muslim Integral (P3KMI) di Jurusan Pendidikan Guru Raudhatul Athfal,Fakultas Keguruan dan Ilmu Pendidikan IAIN Surakarta.

\section{d. Fokus Evaluasi}

Penelitian ini menggunakan model evaluasi CIPP dari Stufflebeam berupa evaluasi yang meliputi :

1) Context untuk mengetahui kebutuhan mahasiswa peserta P3KMI

2) Input untuk mengetahui karakteristik mahasiswa peserta P3KMI

3) Process untuk mengetahui proses pelaksanaan P3KMI

4) Product untuk mengetahui output kemampuan keagamaan mahasiswa peserta P3KMI

\section{e. Teknik Pengumpulan Data}

Untuk mendapatkan data yang signifikan dapat juga ditempuh dengan teknik-teknik tertentu. Sedangkan yang terpenting adalah research. Teknik pengumpulan data yang digunakan dalam penelitian ini adalah: 
1) Angket

Merupakan teknik pengumpulan data dengan cara memberikan sejumlah pertanyaan kepada responden guna mendapatkan data yang baik ${ }^{7}$. Teknik ini digunakan untuk memperoleh data tentang karakteristik mahasiswa dan proses pembelajaran P3KMI.

2) Interview

Lexy J Moeloeng mengartikan wawancara sebagai percakapan dengan maksud tertentu, yang dilakukan oleh dua belah pihak, yaitu pewawancara yang mengajukan pertanyaan dan yang diwawancarai memberikan jawaban ${ }^{8}$. Dalam penelitian ini wawancara digunakan untuk memperoleh data langsung dari subjek mengenai pembelajaran di P3KMI Jurusan Pendidikan Guru Raudhatul Athfal. Interview dilakukan kepada mentee dan mentor. Data ini juga digunakan untuk melakukan validasi data dari hasil observasi.

3) Observasi

Metode observasi adalah Pengamatan dan pencatatan secara sistematis fenomena - fenomena yang diselidiki atau pengamatan yang dilakukan secara sengaja, sistematis, mengenai fenomena sosial dengan gejala psikis untuk kemudian dilakukan pencatatan'. Teknik ini digunakan untuk mengambil data tentang program di P3KMI di Jurusan Pendidikan Guru Raudhatul Athfal secara langsung dan dilaksanakan saat kegiatan P3KMI berlangsung. Observasi dilakukan kepada mentee dan mentor.

4) Dokumentasi

${ }^{7}$ Sugiyono, Metode Penelitian Kuantitatif, Kualitatif, dan R\&DD, (Yogyakarta : Alfabeta, 2012), hlm. 142.

${ }^{8}$ Lexy J. Moleong, Metodologi Penelitian Kualitatif, (Bandung: Remaja Rosda Karya, 2002), hlm. 135.

${ }^{9}$ Hadari Nawawi, Pendidikan dalam Islam, (Surabaya: Al-Ikhlas, 1993), hlm. 7. 
Dokumentasi yaitu teknik yang digunakan untuk mencari data mengenai hal-hal atau variabel yang berupa catatan, transkip, buku, surat kabar, majalah, prasasti, notulen rapat, legger, agenda, dan sebagainya ${ }^{10}$. Teknik ini digunakan untuk mengambil data tentang output kemampuan keagamaan mahasiswa P3KMI di Jurusan Pendidikan Guru Raudhatul Athfal.

\section{f. Teknik Analisis Data}

Teknik analisis data yang digunakan dalam penelitian ini secara umum adalah sebagai berikut, namun secara spesifik akan dikaitkan dengan tahap pengembangan yang dilakukan serta didasarkan pada jenis data dan teknik pengumpulan data yang dilakukan.

1) Analisis Data Kualitatif

Data yang tidak berbentuk angka yang diperoleh dari hasil wawancara dan observasi dalam penelitian ini dianalisis secara interaktif kualitatif, sedangkan teknik pemeriksaan keabsahan data menggunakan triangulasi. Triangulasi data dari penelitian ini diperoleh dengan melakukan cross-check informasi antara informan yang satu dengan informan yang lain. Adapun dari beberapa macam teknik triangulasi, maka pada penelitian ini yang akan digunakan adalah teknik triangulasi sumber.

Dalam proses triangulasi sumber, maka pada evaluasi ini akan digunakan jalan dengan membandingkan (a) hasil wawancara dengan hasil pengamatan, (b) perspektif berbagai stakeholder, dan (c) hasil wawancara dengan dokumen yang berkaitan.

2) Analisis Statistik

Untuk hasil kuesioner yang berbentuk kuantitatif akan dilakukan analisis statistik melalui penghitungan dengan menggunakan program SPSS

${ }^{10}$ Suharsini Arikunto, Prosedur penelitian; suatu pendekatan praktek, (Jakarta: Rineka Cipta,2010) hlm 188. 
11. Hasil yang diperoleh selanjutnya dimaknai dan ditarik kesimpulannya.

\section{Pembahasan Hasil Penelitian}

\section{a. Evaluasi Context}

P3KMI merupakan salah satu program wajib fakultas yang dilaksanakan untuk meningkatkan kemampuan Keagamaan mahasiswa. Program ini diwajibkann bagi seluruh mahasiswa Fakultas Ilmu Tarbiyah dan Keguruan, khususnya bagi mahasiswa baru. Penyelenggaraan P3KMI menunjukkan bahwa tingkat kebutuhan mahasiswa terhadap program ini cukup tinggi. Hal ini terbukti dengan animo mahasiswa untuk mengikuti P3KMI cukup tinggi. Tingginya animo mahasiswa mengikuti program ini disebabkan oleh beberapa alasan. Alasannya antara lain, kewajiban dari fakultas, kurangnya kemampuan mahasiswa dalam bidang Keagamaan.

Mencermati kondisi mahasiswa sekitar dapat dikatakan bahwa penyelenggaraan P3KMI merupakan keputusan yang tepat, karena dapat memenuhi kebutuhan mahasiswa untuk meningkatkan kemampuan Keagamaan. Berdasarkan kondisi di atas dapat disimpulkan bahwa P3KMI merupakan program yang sesuai dengan kebutuhan mahasiswa

\section{b. Evaluasi Input}

Karakteristik Mentee, Karakteristik mentee P3KMI dinilai dari latar belakang pendidikan, dan jenis kelamini mentee dalam mengikuti P3KMI. Berdasarkan hasil analisis dapat dijelaskan bahwa jenis kelamin mentee P3KMI lebih banyak perempuan daripada laki-laki, Hal ini disebabkan jumlah mahasiswa di Jurusan Pendidikan Guru Raudhatul Athfal lebih banyak perempuan daripada laki-laki. Ditinjau dari latar belakang pendidikan mayoritas mahasiswa berasal dari sekolah umum.

Latar belakang pendidikan mentee mayoritas berasal dari sekolah umum sehingga dapat dikatakan bahwa penyelenggaraan P3KMI ini sudah tepat sasaran. Sebab salah satu tujuan P3KMI adalah memberikan kompetensi Keagamaan bagi mahasiswa. 


\section{c. Evaluasi Process}

\section{1) Aktivitas Mentee}

Pada proses pembelajaran mentee sudah melaksanakan kegiatan belajar mengajar dengan baik (optimal). Berdasarkan angket pada pengumpulan data mayoritas berada pada kondisi baik. Optimalnya aktivitas mentee dalam belajar mandiri di luar jam tatap muka di kelas antara lain disebabkan kurangnya dorongan dan pengkondisian orang tua. Beberapa mentor telah mengingatkan mentee untuk belajar di luar tatap muka serta telah memberikan tugas tetapi belum ada tindak lanjut dari mentee. Solusi yang perlu dilakukan terkait aktivitas tersebut adalah pemantauan belajar di luar kelas. Beberapa mentor telah melakukan pemantauan, tetapi secara umum masih belum mampu mendorong mentee untuk mengintensifkan belajar mandiri di luar jam tatap muka. Selain itu penyelenggara perlu mengingatkan kepada seluruh mentee agar meningkatkan kualitas belajar untuk mencapai hasil yang maksimal.

\section{2) Aktivitas Mentor}

Pengelolaan pembelajaran oleh mentor berpengaruh terhadap keberhasilan pembelajaran P3KMI. Pengelolaan kegiatan belajar mengajar di kelas yang baik dapat meningkatkan prestasi mentee. Terkait kemampuan mentor dalam pengelolaan kelas berdampak pada tinggi rendahnya prestasi belajar peserta program yang mengikuti proses kegiatan belajar mengajar. Berdasarkan data dari angket mentor mayoritas berada pada kondisi baik dan cukup.

Pendapat mentee tentang pembelajaran oleh mentor selaras dengan temuan peneliti ketika mengadakan pengamatan langsung proses belajar mengajar di kelas. Dari observasi kelas diperoleh aktivitas mengajar yang dilakukan mentor selama pembelajaran termasuk kategori cukup yang ditunjukkan oleh perolehan hasil observasi tersebut.

Salah satu hal yang dikeluhkan mentee adalah mentor mengajar terlalu cepat. Hal ini juga ditemui peneliti ketika mengadakan observasi kelas. Mentor melakukan pembelajaran seperti pada kegiatan kelas program formal. Pola dan pendekatan 
yang digunakan masih belum sesuai untuk kalangan pelajar yang telah dewasa. Langkah yang dilakukan untuk mengatasi hal tersebut adalah dengan memperbaiki pendekatan pembelajaran yang disesuaikan dengan kemampuan orang dewasa.

Beberapa kelemahan pembelajaran di sebabkan kekurangtahuan mentor tentang pembelajaran yang seharusnya dilakukan pada P3KMI. Hal tersebut disebabkan mentor masih belum mengikuti pelatihan tentang pembelajaran P3KMI. Tanpa pengetahuan dan pemahaman yang baik tentang P3KMI maka mentor tidak dapat menjalankan tugasnya dengan baik. Pelatihan mungkin menjadi jalan yang tepat untuk kepentingan ini. Selain itu terkait pengetahuan dan pemahaman mentor dalam bidang PLS di P3KMI dapat dilakukan dengan membaca dan bertukar pikiran dengan sesama mentor.

\section{d. Evaluasi Product}

Berdasarkan data dokumentasi bahwa sebanyak 94,33\% untuk ujian Baca, 60,37\% untuk ujian Tulis, dan 33,96\% untuk ujian Hafalan. Sedangkan yang remidi untuk ujian Baca 30,19\%, ujian tulis sebanyak 39,63\%, dan ujian hafalan sebanyak 66,04\%. Berkaitan dengan peningkatan prestasi belajar pada P3KMI, perlu dilakukan upaya untuk lebih meningkatkan prestasi yaitu dengan cara meningkatkan kualitas mentor dan pemberian fasilitas atau sarana prasarana yang menunjang P3KMI. Selain itu mentee harus memperbaiki belajarnya di kelas maupun di luar kelas. Penyelenggaraan program akan berjalan dengan baik jika mendapat dukungan dari semua komponen program.

\section{e. Hubungan antara Context, Input, Process dan Product}

P3KMI merupakan salah satu bentuk pendidikan non formal pada program wajib Fakultas yang bertujuan membimbing mahasiswa untuk memiliki kompetensi yang baik dalam kemampuan Keagamaan. Pemberian program ini dimaksudkan agar mahasiswa yang belum memiliki kemampuan dalam Keagamaan agar mampu dan bisa menguasainya.

Pada penyelenggaraan P3KMI berdasarkan dokumentasi ternyata nilai rata-rata hasil ujan untuk kemampuan 
Keagamaan dalam hal Baca Tulis termasuk baik, dengan presentase kelulusan sebesar 69,81\%, sedangkan untuk kategori hafalan masih kurang dengan presentase kelulusan sebesar 33,96\%. Dilihat dari Aspek context program ini sudah mendapat dukungan yang memadai dari Fakultas berupa biaya penyelenggaraan program dan sarana-prasarana.

Beberapa mahasiswa yang tidak lulus dipengaruhi oleh aspek input karena mereka berasal dari sekolah umum dan belum mendapat background keagamaan yang memadai. Selain itu, penyelenggraannya juga dipengaruhi oleh masalah mentor yang dalam pembelajaran belum mampu menyampaikan materi dengan tepat hal ini disebabkan oleh kurangnya pelatihan yang diberikan kepada mentor dalam penyelenggaran P3KMI dan kurangnya fasilitas yang diberikan kepada para mentee.

Prestasi belajar peserta program dipengaruhi oleh proses yang berlangsung selama penyelenggraan program. Proses pembelajaran yang baik akan mendorong pencapaian prestasi belajar yang baik dan sebaliknya. Hasil penelitian menunjukkan bahwa mentor telah menjalankan tugas dengan baik menggunakan berbagai metode dan pendekatan dalam pembelajaran, menjalin komunikasi dengan mentee, menggunakan media dan mendorong keaktifan mentee dlam mengikuti kegiatan belajar. Perlakuan ini dilakukan untuk meningkatkan aktivitas mentee dalam proses pembelajaran tanpa meninggalkan proses pembelajaran yang dilakukan terhadap orang dewasa.

Hasil penelitian menunjukkan pembelajaran mentee P3KMI sudah optimal. Berdasarkan angket yang diberikan pada mentee aktivitas belajar mentee termasuk dalam kategori baik.

Berdasarkan uraian di atas dapat disimpulkan bahwa manfaat P3KMI penting dalam peningkatan kualitas kompetensi keagamaan . Kondisi ini, perlu diperbaiki dari segi context, input, process dan product. Mentor, mentee dan pihak fakultas perlu berupaya mendorong penyelenggaraan P3KMI yang lebih baik dan optimal. Hal ini diperlukan untuk peningkatan kualitas sumberdaya mahasiswa di pendidikan khususnya dalam bidang kompetensi keagamaan. 


\section{Simpulan}

Berdasarkan hasil penilitian evaluasi yang dilaksanakan di program P3KMI Jurusan PGRA FITK IAIN Surakarta dari pembahasannya dapat disimpulkan sebagai berikut:

1. Evaluasi Context

Program p3kmi ini sangat dibutuhkan oleh mahasiswa. Alasannya antara lain karena program p3kmi merupakan kewajiban dari fakultas, dan kurangnya kemampuan mahasiswa dalam bidang Keagamaan.

2. Evaluasi Input

Karakteristik mahasiswa program P3KMI dilihat dari jenis kelamin, terdiri dari 51 perempuan dan 2 lakilaki. Sedangkan dilihat dari latar belakang pendidikan, terdiri dari 43 orang lulusan umum (SMA/SMK) dan 11 orang lulusan keagamaan (MA/Ponpes).

3. Evaluasi Proses

Hasil evaluasi proses menunjukkan aktivitas mentee dalam kategori kurang dengan presentase baik sebesar $18,86 \%$, presentase cukup sebesar 35,84\%, dan presentase kurang sebesar 45,28\%. Sedangkan hasil evaluasi proses untuk aktivitas mentor dalam kategori baik dengan presentase sebesar $85,71 \%$.

4. Evaluasi Product

Berdasarkan tes yang telah dilaksanakan, hasil belajar mahasiswa yang masuk kategori lulus sebesar 18,86\% dan yang mengulang/remidi sebesar 81,14\%.

Berdasarkan kesimpulan dari hasil penelitian, kepada pihak terkait disarankan untuk melakukan dan menindaklanjuti hasil temuan sebagai berikut.

1. Kepada Dekan FITK penyelenggaraan program p3kmi perlu dipertahankan dan ditingkatkan hal ini dapat dilakukan dengan cara menyediakan sarana-prasarana program dan pelatihan bagi para mentor sehingga kualitas program meningkat.

2. Kepada para Mentor, diharapkan dapat meningkatkan kualitas dan kemampuan mengajar agar mentee dapat 
menerima materi pembelajaran dengan baik optimal.

3. Kepada para mentee diharapkan dapat meningkatkan kemampuannya dibidang Baca, Tulis dan Hafalan agar dapat lulus p3kmi dengan nilai sesuai dengan standar yang telah ditetapkan. 


\section{DAFTAR PUSTAKA}

Hadari Nawawi, Pendidikan dalam Islam, Surabaya: Al-Ikhlas, 1993.

Moleong, Lexy J, Metodologi Penelitian Kualitatif, Bandung: Remaja Rosda Karya, 2002.

Muhaimin, Wacana Pengembangan Pendidikan Islam, Yogyakarta: Pustaka Pelajar, 2004.

Provus, M., Discrepency evaluation, Barkeley: MacCutchan, 1971.

Stufflebeam, DL, Educational evaluation and decising making, Illionis : Hasca Illinois Pecocok Publicers Inc, 1972.

Sugiyono, Metode Penelitian Kuantitatif, Kualitatif, dan R\&D, Yogyakarta: Alfabeta, 2012.

Suharsimi Arikunto, Dasar-Dasar Evaluasi Pendidikan, Jakarta: Rhineka Cipta, 1998.

, Prosedur penelitian; suatu pendekatan praktek, Jakarta: Rineka Cipta, 2010.

Toto Suharto \& Ja'far Assagaf, Membendung Arus Paham Keagamaan Radikal Di Kalangan Mahasiswa PTKIN, Ponorogo: At Tahrir, 2014.

Tyler, RW, Basic Principles of Curriculum and Instruction, Chicago: University of Chicago, 1967. 